\title{
EL DERECHO DE SUPERFICIE EN EL CODIGO CIVIL Y COMERCIAL DE LA NACION Y SU IMPLICANCIA NOTARIO REGISTRAL
}

\author{
Por María Adriana Garay
}

SUMARIO- I. INTRODUCCION. II. ANTECEDENTES HISTORICOS. III. CONCEPTO . IV. NATURALEZA JURIDICA. V. MODALIDADES. VI. PLAZOS. VII. LEGITIMACION. VIII. LA SUPERFICIE Y LA PROPIEDAD HORIZONTAL. IX. FORMAS DE ADQUISICION DE LA SUPERFICIE ASPECTOS NOTARIALES Y REGISTRALES. X. FACULTADES DEL SUPERFICIARIO Y DEL DOMINIS SOLUM. XI. DESTRUCCCION DE LA PROPIEDAD SUPERFICIARIA. XII. EXTINCION. XIII. NORMAS APLICABLES A LA SUPERFICIE. DERECHO DE SUPERFICIE Y PROPIEDAD SUPERFICIARIA. XIV. IMPLICANCIA ECONOMICA E IMPORTANCIA DEL ROL DEL ESCRIBANO. XV.CONCLUSION.

\section{RESUMEN:}

El derecho real de superficie contemplado en el Código Civil y Comercial de la Nación permite aplicar el mismo no sólo a forestaciones y plantaciones sino a construcciones. El objeto del mismo es de esta manera mucho más amplio lo cual obliga a su análisis jurídico en la normativa de fondo y en las resoluciones catastrales y registrales, en las cuales el notario tendrá un rol fundamental no sólo en el asesoramiento de la multiplicidad de negocios a realizarse sino en la instrumentación de los mismos.

\section{ABSTRACT}

The real surface right contemplated in the Civil and Commercial Code of the National lowsit to be applied not only to af forestation and plantations, but to constructions.

Its purposeist husmuch broader, which requires its legal analysis in the substantive regulations and in cadastral and registry resolutions, in which the notary will have a fundamental role not only in advising on the multiplicity of business es to be carried out but in the instrumentation of thesame.

PALABRAS CLAVE: superficie. normativa. notario.

KEY WORDS: surface. normative. notary.

\footnotetext{
1 Profesora Titular de Instrumentos de Derechos Reales y Registral, Facultad de Derecho, UN de Lomas de Zamora, sede Córdoba. Profesora Adjunta Universidad Blas Pascal. Docente de Privado V Reales de la Facultad de Derecho de la UNC. Miembro del Instituto Notario Registral de la Academia Nacional de Derecho de Córdoba.
} 


\section{Introduccion}

El derecho de superficie es un derecho real que a los largo de la historia en nuestro País, pasó desde ser prohibido a regularse como derecho de superficie forestal, encontrándonos ahora con un derecho real nuevo que admite la plantación, forestación y edificación. La relevancia jurídica de este derecho así como su proyección económica que permite al dueño del suelo constituir con un superficiario diferente modalidades no pueden ser pasadas por alto, más aún en épocas como las que atravesamos donde debemos fomentar diferentes negocios inmobiliarios. Haremos pues un análisis de su regulación en el Código Civil y Comercial de la Nación y su incidencia es los aspectos notariales y registrales.

\section{Antecedentes historicos.}

El derecho de superficie nació en Roma, respondía al principio "superficie solo cedit" según el cual, cuanto se construía o plantaba en la superficie de un inmueble pertenecía a su propietario por accesión, que era un modo de adquirir el dominio del derecho romano.

El Código de Napoleón no la receptó por ser considerado como una forma de sofocación de la propiedad, aunque la jurisprudencia la aceptó. Fue regulada en los Códigos Civiles de Prusia (1794) y de Austria (1811) como propiedad separada. ${ }^{2}$

En el Código de Vélez, conforme a la política restrictiva sobre multiplicidad de derechos, expresamente lo prohibió, así el artículo 2614 del Código Civil derogado, establecía " Los propietarios de bienes raíces no pueden constituir sobre ellos derechos enfitéuticos, ni de superficie, ni imponerles censos ni rentas que se extiendan a mayor término que el de cinco años, cualquiera sea el fin de la imposición; ni hacer en ellos vinculación alguna."

Asimismo en la nota al artículo 2503, Vélez explica en forma magistral las razones que expulsaron el derecho de superficie de la mayor parte de las legislaciones del siglo XIX. ${ }^{3}$

En el Derecho Comparado Moderno existe una tendencia al resurgimiento del derecho real de superficie, tanto referido al suelo como al subsuelo. Así es admitido por las legislaciones de España, Italia, Francia, Portugal, Alemania, Suiza, Austria, Bélgica, Holanda, Japón, Canadá, Bolivia, Perú, Cuba, entre otros. En algunos Países se aplicó sólo a construcciones y no plantaciones como en Alemania, Suiza, Italia, Francia, España, Portugal, Japón, Quebec, Holanda ${ }^{4}$

Actualmente existe un resurgimiento del derecho de superficie, justificado económica-

2 Codigo Civil y Comercial Comentado, Alterini, obra citada,p. 135.

3 Nota:2503. No enumeramos el derecho del superficiario, ni la enfiteusis, porque por este código no pueden tener lugar. El derecho del superficiario consistía en poder hacer obras, como edificar casas, plantar árboles, etc., adherentes al suelo, sobre las cuales tenía un derecho de propiedad, independiente del de propietario del terreno, el cual sin embargo, podía por derecho propio, hacer sótanos y otros trabajos subterráneos bajo de la misma superficie que pertenecía a otro, con tal que no perjudicase los derechos del superficiario, así como el superficiario, no podía deteriorar el fondo del terreno.

En Roma, según las reglas del Derecho civil, la propiedad de la superficie no podía ser distinta de la propiedad del suelo, lo que importaba decir no sólo que el propietario del suelo venía a ser propietario de todas las construcciones y plantaciones que él hubiese hecho con los materiales de otro, o que un tercero hubiese hecho en el suelo con sus materiales, sino también que el propietario del suelo no podía enajenar la superficie en todo o en parte, separándola del suelo; y si él, por ejemplo, hubiese vendido su casa solamente sin vender el suelo, el adquirente no venía a ser propietario de ella.

Mas después el Derecho Pretoriano concedió al adquirente de la superficie una acción y un interdicto especial, cuando se tratase de una concesión a perpetuidad, o por un largo tiempo.

El derecho de superficie desde entonces, como una desmembración del derecho de propiedad, podía ser transmitido y enajenado en todo o en parte, gravado con usufructo o servidumbre, venir a ser el objeto de una acción de partición entre los herederos, si estaba indiviso, y susceptible de ser adquirido por prescripción. L. 1, \$\$ 6 hasta 9, Dig. "De adq. velamitt. possess.".

Hemos juzgado que era más conveniente aceptar el derecho puro de los romanos y estar a las resoluciones generales sobre lo que se edificase y plantase en suelo ajeno. El derecho de superficie desmejoraría los bienes raíces y traería mil dificultades y pleitos con los propietarios de los terrenos...."

4 Mariani de Vidal y Abella, obra citada, p. 363 y sgtes. 
mente en la necesidad de no tener capitales inactivos al mismo tiempo que se facilita la construcción o forestación.

En nuestro País la postura reacia a su admisión se mantuvo en el Anteproyecto Bibiloni de 1926, el Proyecto de 1936 y en el Anteproyecto Llambías de 1954.

Comenzó a vislumbrarse la necesidad de admitir este derecho real en el II Congreso Nacional de Derecho Civil, Córdoba 1937 y las X Jornadas Nacionales de Derecho Civil celebradas en Corrientes en 1985. Asimismo el Proyecto de Unificación Legislativa Civil y Comercial de 1987 y el Proyecto de Código Unico de 1987 cobijaron la creación del derecho de superficie. El Proyecto de Unificación de los Códigos Civil y de Comercio de 1998 lo recepta como un derecho real autónomo, tanto para construir como para forestar. ${ }^{5}$

El derecho de superficie, sólo forestal fue introducido por nuestro derecho por la ley 25.509, que se sanciono el 14 de noviembre de 2001 promulgada el 11 de diciembre de 2001 y publicada en el Boletín Oficial el 17 de diciembre de 2001. Se trató de una ley complementaria al Código Civil y agregabacomo inciso 8 del artículo 2503 del Código Civil derogado, a la superficie forestal como derecho real enumerado.

Uno de los objetivos de la ley fue procurar que la explotación forestal alcance un desarrollo más sostenido y extendido, ampliar la franja de potenciales interesados, implementar un sistema forestal industrial organizado que contribuya a la desconcentración del mercado y a la desarticulación de los monopolios multinacionales, convocando a pequeños colonos o chacareros que no contaban con capital suficiente para la explotación y a industriales madereros que no disponían de materia prima a sumarse a los planes de forestación. ${ }^{6}$

La ley 26.994 de sanción del nuevo Código Civil y Comercial de la Nación deroga expresamente la ley 25.509 , enumerando el Código vigente entre los derechos reales admitidos a la superficie (art 1887 inc. g).

\section{Concepto}

El artículo 2114, Titulo 8 del Libro Cuarto, da un concepto a saber:

Artículo 2114. Concepto El derecho de superficie es un derecho real temporario, que se constituye sobre un inmueble ajeno, que otorga a su titular la facultad de uso, goce y disposición material y jurídica del derecho de plantar, forestar o construir, o sobre lo plantado, forestado o construido en el terreno, el vuelo o el subsuelo, según las modalidades de su ejercicio y plazo de duración establecidos en el título suficiente para su constitución y dentro de lo previsto en este Título y las leyes especiales.

El Código recepta la superficie en forma amplia, ya sea edificada o agraria (plantaciones o forestaciones). Se caracteriza como un derecho real autónomo (1887, temporario (artículo 2117 ), transmisible $(2119)$, registrable $(1890,1892)$ que recae sobre inmuebles (2114) y que se ejerce por la posesión (1891).

5 Art 2018 del citado Proyecto.

6 Kiper, Claudio, obra citada, p. 16 y sgtes. 


\section{Naturaleza juridica}

En cuanto a su naturaleza jurídica el Dr. Gabriel Ventura, Titular de la Cátedra A de la Facultad, de Derecho de la UNC, considera que se trata de un derecho real sobre cosa propia. Así expresa: "Es correcta la tipificación del derecho de superficie(... .)como sobre cosa propia (...) ya que la esencia conceptual de esta clasificación (sobre cosa propia o ajena) radica en en la mayor o menor amplitud de las facultades del titular del derecho ...". y agrega "...si el derecho real es sobre cosa propia, como regla general el titular tendrá plena disposición jurídica de la cosa: podrá transferirla, gravarla, le podrá ser embargada y hasta subastada por sus acreedores, mientras que si se trata de un derecho real sobre cosa ajena, salvo algunos supuestos como el usufructo, la cosa que constituye su objeto no podrá ser enajenada ni gravada .. ). ${ }^{7}$ En contra podemos citar en otros ${ }^{8}$. Estos autores sostiene que se trata de un derecho mixto, en donde la superficie es un derecho real sobre cosa ajena si se otorga a su titular el derecho a plantar, forestar o construir sobre terreno (vuelo o subsuelo) de otro y hacer suyo lo plantado, forestado o construido, naciendo entonces la propiedad superficiaria (que recaerá sobre cosa propia: lo plantado o construido), recayendo también sobre cosa propia si existe propiedad superficiaria desde el inicio, es decir si el derecho de superficie se concede sobre plantaciones o construcciones ya existentes (artículo 1888). ${ }^{9}$ Es decir según estar posturas mayoritarias mientras no se construya, foreste o plante, el derecho recae sobre un inmueble ajeno, aclarando Kiper que es sobre cosa propia si hay plantaciones, forestaciones o construcciones, no mientras el espacio este vacío.

\section{Modalidades.}

Cualquiera sea la forma que se adopte siempre existirá un derecho real desde su constitución.

El derecho puede asumir dos modalidades ${ }^{10}$.

Artículo 2115. Modalidades El superficiario puede realizar construcciones, plantaciones o forestaciones sobre la rasante, vuelo ${ }^{11}$ y subsuelo del inmueble ajeno, haciendo propio lo plantado, forestado o construido.

También puede constituirse el derecho sobre plantaciones, forestaciones o construcciones ya existentes, atribuyendo al superficiario su propiedad. En ambas modalidades, el derecho del superficiario coexiste con la propiedad separada del titular del suelo.

a) Primera modalidad. Derecho a edificar, plantar o forestar:

Aparece cuando el derecho real constituido permite construir, plantar o forestar en suelo ajeno y adquirir la propiedad de lo edificado o plantado con independencia de la propiedad del suelo.

\footnotetext{
7 Para mayor profundidad del tema ver Ventura, Gabriel, Los Derechos Reales incorporados en el Código Civil y Comercial de la nación y la Publicidad Registral, en Academia Nacional de Derecho de Córdoba.

8 Cossari Nelson y Cossari Leandro, Tratado de Derecho Civil y Comercial, Tomo VI, Derechos Reales, La Ley, Bs As, 2016, p. 905. En igual sentido respecto que se trata de un derecho mixto: Mariani de Vidal y Abella, obra citada, p.367; Kiper Claudio, obra citada, p.18 y sgtes.

9 En igual sentido respecto al derecho de superficie como derecho real mixto (propia y ajeno) las XIX Jornadas Nacionales de Derecho Civil reflejaron en el punto II de las conclusiones de lege data de la Comisión IV, por voto mayoritario (25 votos).

10 En tal sentido se ha criticado el termino modalidad que corresponde a la condición, plazo y cargo como "modalidades de los actos jurídicos": Alterini, Código Civil y Comercial, obra citada, p. 158.

11 La terminología de "espacio aéreo" y no la de "vuelo" es correctamente utilizada en el art 2116. El término "rasante" que apunta al plano que se encuentra el nivel del terreno, pudo reempl3azarse directamente por la de "terreno". Ver al respecto Alterini, Código Civil y Comercial, obra citada, p. 159.
} 
b)Segunda modalidad. Propiedad superficiaria.

Recae sobre la construcción o plantación que ya existe y que pasa a ser propiedad del superficiario, en forma separada de la propiedad del suelo, originándose la propiedad superficiaria, cuyo uso, goce y disposición corresponden al superficiario.

Artículo 2116. Emplazamiento El derecho de superficie puede constituirse sobre todo el inmueble o sobre una parte determinada, con proyección enel espacioaéreo o en el subsuelo, o sobre construcciones ya existentes aun dentro del régimen de propiedad horizontal. La extensión del inmueble afectado puede ser mayor que la necesaria para la plantación, forestación o construcción, pero debe ser útil para su aprovechamiento.

Este artículo amplia el 2115, ya que establece que el derecho pueda situarse con proyección en el espacio aéreo o en el subsuelo ${ }^{12}$, o sobre construcciones o plantaciones ya existentes aun dentro del régimen de propiedad horizontal. Puede pues proyectarse sobre el suelo o el subsuelo y también recaer sobre una mayor extensión que la construcción o plantación, si es útil para el aprovechamiento de las mismas. De esta forma se evita la creación innecesaria de otros derechos reales como la servidumbre de paso a los fines de comunicar ciertos sectores con los destinados a construcción o plantación.

El artículo 2116 permite la constitución de superficie aun respecto de inmuebles afectados a propiedad horizontal y la construcción sobre todo el inmueble o sobre una parte de él. ${ }^{13}$

\section{Plazos}

Está regulado en el artículo siguiente:

Artículo 2117. Plazos El plazo convenido en el título de adquisición no puede exceder de setenta años cuando se trata de construcciones y de cincuenta años para las forestaciones y plantaciones, ambos contados desde la adquisición del derecho de superficie. El plazo convenido puede ser prorrogado siempre que no exceda de los plazos máximos.

Tal como surge del citado artículo, se establece un plazo máximo de duración de 70 o de 50 años, según se trate de construcciones o de forestaciones y plantaciones, respectivamente.

El plazo debe ser contado desde la adquisición del derecho real de superficie, o sea desde que concurren título y modo suficiente. Opinamos que entre las partes, el plazo debe computarse desde que se reúnen título y modo, dado que es en ese momento en que se constituye el derecho real. En cambio respecto de los terceros, resulta razonable tomar la fecha del título inscripto (art 1893). ${ }^{14}$ Resulta susceptible de ser prorrogado y aún pactar la renovación automática, pero entendemos que nunca el plazo originario más la renovación deben exceder los plazos máximos previstos. ${ }^{15}$

\footnotetext{
12 Bodegas, playas de estacionamiento subterráneas, etc.

13 Esta parte material se determinara a través de un plano que acompañara al instrumento de constitución y que deberá registrarse para su oponibilidad. 14 En igual sentido, Alterini, Código Civil y Comercial, obra citada, p. 162.

15 En igual sentido Mariani de Vidal y Abella, obra citada, p. 372. En contra: Alterini J y Alterini H, en Código Civil y Comercial, obra citada. P. 162 para quienes pactada una renovación el nuevo plazo convenido se contará desde la fecha del acto de renovación.
} 


\section{Legitimacion}

Están facultados para constituir el derecho de superficie los titulares de los derechos reales de dominio, condominio y propiedad horizontal En tal sentido el artículo 2118 dispone:

Artículo 2118. Legitimación Están facultados para constituir el derecho de superficie los titulares de los derechos reales de dominio, condominio y propiedad horizontal.

Son pues parte en este contrato, los titulares de dominio, condominio o propiedad horizontal, que justifiquen la calidad de tales con título inscripto. De esta manera no podrán hacerlo quienes tengan una relación personal como los locatarios, comodatarios, depositarios, o adquirentes por boleto de compraventa.

Si el inmueble está en condominio, deberán prestar su conformidad todos los condóminos para la constitución de derecho de superficie sobre toda la cosa o una parte material de ella (art 1990). No es admisible la constitución del derecho por uno de los condóminos respecto de su parte indivisa por la naturaleza del derecho que se crea.

Los titulares de dominio, condominio o propiedad horizontal, así como a aquellos a cuyo favor se constituya el derecho de superficie, pueden ser personas físicas o jurídicas.

\section{La superficie y la propiedad horizontal}

Pueden darse distintas situaciones:

a) Sobre el inmueble sometido a Propiedad Horizontal

Esta posibilidad surge del artículo 2126 cuando expresa que el derecho de superficie "puede constituirse (...) sobre construcciones ya existentes aun dentro del régimen de propiedad horizontal".

Si se trata de construir nuevos pisos sobre una edificación ya existente o sobre el terreno, debe tenerse en cuenta que tanto el terreno, como los techos, azoteas, etc. son cosas necesariamente comunes (art 2041).

Es decir, el derecho de superficie puede establecerse sobre construcciones ya existentes o conceder al superficiario el derecho a realizar nuevas construcciones. En ambos casos se requerirá de unanimidad de los copropietarios (artículo 2052).

b) Sobre la Unidad funcional.

El propietario de una unidad funcional puede constituir derecho de superficie que se extiende conforme art 2039 a la parte privativa, la parte indivisa del terreno, de las cosas y partes de uso común del inmueble indispensables para mantener su seguridad, y puede abracar una o más complementarias destinadas a servirlas.

c) Conjuntos Inmobiliarios

Conforme el CCCN el conjunto inmobiliario es una propiedad horizontal especial (art 2075). Podrá pues el propietario de la unidad funcional en un conjunto inmobiliario conceder el derecho de superficie, ya sea para enajenarla construida o en proceso de construcción (art 2077).

También podrán todos los propietarios en forma unánime (art 2052) constituir derecho 
de superficie sobre las partes comunes del conjunto. ${ }^{16}$

d) Propiedad Horizontal sobre la propiedad separada del terreno.

El superficiario puede someter la construcción al régimen de la propiedad horizontal, y transmitir y gravar las unidades funcionales en forma independiente el terreno durante el plazo de duración del derecho de superficie (artículo 2120, 2do párrafo CCCN), debiendo para ello afectarlo al régimen de propiedad horizontal.

Se tratará de unan propiedad horizontal especial, pues no comprenderá el terreno que permanecerá en cabeza del nudo propietario. .Extinguido el derecho de superficie, se extingue el derecho de propiedad horizontal constituido por el superficiario, debiendo desafectarse del régimen de propiedad horizontal conforme las disposiciones que rigen la misma.

\section{Formas de adquisicion de la superficie aspectos notariales y registrales}

Está regulada la adquisición en el artículo 2119 a saber:

Artículo 2119. Adquisición El derecho de superficie se constituye por contrato oneroso o gratuito y puede ser transmitido por actos entre vivos o por causa de muerte. No puede adquirirse por usucapión. La prescripción breve es admisible a los efectos del saneamiento del justo título.

a) Adquisición derivada por actos entre vivos.

El acto jurídico debe ser realizado por quien es capaz y este legitimado y al tratarse de un inmueble cumplirse con la solemnidad de la escritura pública (art 1017) además del modo suficiente. Deberá inscribirse en el Registro de la Propiedad para la oponibilidad a terceros. En cuanto a la técnica registral dependerá de lo que disponga las disposiciones administrativas locales. Así en Capital Federal se asentará en la matrícula correspondiente al dominio en el rubro gravámenes el derecho de superficie. Se abrirá a su vez una submatrícula que contara con los datos precisos de la misma conforme un plano. Al respecto la Disposición Técnica Registral 3/2015 de Capital Federal expresa:17

16 Mariani de Vidal y Abella, obra citada, p. 375.

17ARTÍCULO $1^{\circ}$ - Las escrituras públicas por las que se constituya elderecho real de superficie, que se presenten para su inscripción,deberán ser acompañadas de una solicitud en la que se consignen losdatos fijados en el artículo $8^{\circ}$ del Decreto 2080/80 (T.O. Dec. N $466 / 99$ ), en la medida que estos resulten de aplicación a la especie, ylos que en el artículo $2^{\circ}$ de esta Disposición se establecen.

ARTÍCULO $2^{\circ}$ - Serán calificadas verificando que de ellas resulten,además de la determinación física y jurídica de los inmuebles y de laidentificación de los otorgantes, en los términos de la Ley $\mathrm{N}^{\circ} 17.801$ ydel artículo 305 del Código Civil y Comercial, los siguientes datos:

a) Extensión y modalidades del derecho superficiario;

b) Plazo de duración, de conformidad con el artículo 2117 del Código Civil y Comercial;

c) Si el derecho real de superficie fuere constituido sólo sobre unaparte determinada del inmueble, su extensión, medidas y demás especificaciones que resulten necesarias para su íntegraindividualización deberán surgir de plano confeccionado por unprofesional con constancias del plano y los datos del profesional que lo confeccionódeberán constar en el título constitutivo y en la solicitud deinscripción. Por no ser objeto de cotejo no se deberá adjuntar el planoal documento traído a registración, ni tampoco se exigirá que haya sido registrado o aprobado por el organismo catastral del Gobierno de laCiudad de Buenos Aires. (Inciso c) sustituido texto según art. $1^{\circ}$ de la Disposición Técnico Registral No 22/2016 del Registro de Propiedad Inmueble de la Capital Federal B.O. 21/11/2016.)

ARTÍCULO $3^{\circ}-$ La inscripción del derecho real de superficie se practicará en la matrícula donde conste inscripto el dominio o el condominio, en el rubro referido a sus gravámenes y restricciones y haciendo constarla constitución del derecho real, el plazo convenido en su título o sucondición resolutoria, los datos personales del superficiario, elnúmero y fecha de la escritura, el nombre del escribano autorizante ysu registro notarial, los certificados utilizados, si el negocio hasido gratuito u oneroso indicando, en su caso, el precio establecido, yla fecha y número de presentación del documento. Inscripto este últimoen forma definitiva, sólo se procederá a la apertura de la submatrícula “SUPERFICIE" - manteniendo el número de la de origen- en el supuesto quese ruegue la inscripción de transferencia, constitución de derechosreales de garantía o afectación al régimen de propiedad horizontalsobre el derecho del superficiario, conforme lo permite el artículo2120 del CCyC. 
El Registro de la Provincia de Córdoba, en la Normativa Técnico Registral; resolución General 4/2015, dispone:

\section{Derecho real de Superficie}

101.1. Serán susceptibles de registración los documentos por los cuales el titular de dominio disponga o grave el inmueble de su propiedad y que no turbe el derecho del superficiario (conforme artículo 2.121 del Código Civil y Comercial de la Nación).

101.2. Serán susceptibles de registración los documentos por los cuales el superficiario realice lo siguientes actos, a saber: a)gravar el derecho de construir, plantar o forestar; b)gravar la propiedad superficiaria (lo construido, lo plantado o forestado); c)afectar la construcción al régimen de propiedad horizontal; $y$ d) transmitir o gravar como inmuebles independientes las viviendas, locales $u$ otras unidades privativas; ello, siempre durante el plazo de vigencia del derecho de superficie y sin necesidad de consentimiento del propietario (artículo 2.120 del Código Civil y Comercial de la Nación).

101.3. Respecto de las escrituras públicas de afectación del inmueble al régimen de Superficie, serán requisitos a calificar los siguientes, a saber: a)que se haya instrumentada por escritura pública; b) que se publicite el plazo convenido por las partes (artículos 2.117 y 2.125 del Código Civil y Comercial de la Nación); c) que se constituya sobre el inmueble, o sobre una parte determinada, sobre el espacio aéreo, sobre el subsuelo o sobre construcciones existentes aún dentro del régimen de propiedad horizontal (sobre una unidad que surge del régimen de PH); d)que se acompañe Plano de Mensura, salvo cuando el derecho de superficie abarque la totalidad de/l/los inmueble/s afectado/s; e) que sea constituido por el titular del derecho real de dominio, condominio o propiedad horizontal; y f) que los actos jurídicos que realice el superficiario sean celebrados dentro del plazo de vigencia del derecho de superficie, sin necesidad del consentimiento del titular dominial.

101.4. En el supuesto que constare en los asientos registrales, por así haberse rogado, que el superficiario no puede afectar la construcción al régimen de propiedad horizontal sin el con-

\footnotetext{
del inmueble, el objeto y la extensión del derecho de superficie y su determinación según el plano respectivo, si fuere parcial; b) en el rubro titularidad del superficiario, sus datos personales, la individualización de la escritura de constitución, el plazo convenido y demás condiciones relativas al negocio causal ,replicando los contenidos del asiento de constitución.
}

ARTÍCULO $5^{\circ}-$ La extinción del derecho real de superficie deberá serrogada expresamente y se inscribirá tanto en la matrícula de origencomo en las correspondientes submatrículas.

ARTíCULO $6^{\circ}$ - Las certificaciones (Art. 23 Ley $N^{\circ} 17.801$ ) solicitadaspara la constitución de un derecho de superficie se anotarán en lamatrícula de origen. El pedido de certificación referido a unaSuperficie determinada se anotará en la correspondiente submatrícula.Las solicitudes de informes (Art. 27 de la Ley $\mathrm{N}^{\circ} 17.801$ ) por inmueblessobre los cuales consten inscripciones relativas a derechos reales desuperficie, se expedirán conforme su rogatoria.

ARTÍCULO $7^{\circ}-$ Si de la escritura de constitución del derecho desuperficie resulta la prohibición para el superficiario de afectar suderecho a propiedad horizontal sin el consentimiento del titular dedominio, se hará constar esa circunstancia en el asiento respectivo; elautorizante del documento deberá transcribir la parte pertinente deltestimonio en la correspondiente solicitud de inscripción.

ARTÍCULO $8^{\circ}-$ La Dirección de Inscripciones Reales y Publicidadaprobará los modelos y los textos de los asientos necesarios parapracticar las registraciones sobre la base de lo dispuesto en lapresente Disposición.

ARTÍCULO $9^{\circ}$ - La presente Disposición Técnico Registral entrará en vigencia a partir del $1^{\circ}$ de agosto de 2015.

ARTÍCULO 10. - Póngase en conocimiento de la Secretaría de AsuntoRegistrales y de la Subsecretaría de Coordinación y Control de GestiónRegistral. Hágase saber al Colegio de Escribanos de la Ciudad de BuenosAires, al Colegio Público de Abogados de la Capital Federal y demásColegios Profesionales. Notifíquese a las Direcciones de RegistracionesReales y Publicidad, de Interpretación Normativa y ProcedimientoRecursivo, de Registraciones Especiales y Publicidad Indiciaria, y deApoyo Técnico y Fiscalización Interna y, por su intermedio, a susrespectivos Departamentos y Divisiones. 
sentimiento del titular de dominio, deberán observarse los documentos que no cumplan con la intervención de éste último.

101.5. La afectación del inmueble al régimen de superficie se registrará en la parte superior de la o las matrículas afectada/s donde se dejará constancia de la apertura de la matrícula "SA" específica para el derecho real de superficie, utilizando hasta la confección e impresión de los nuevos folios, las planillas A existentes. Si el superficiario afectare su derecho a propiedad horizontal, el documento se registrará en la forma de estilo, tomando como referente la o las matrículas "SA" de origen del derecho real de superficie.

(lo resaltado nos pertenece).

101.6. Los documentos portantes de gravámenes, medidas cautelares, cancelaciones y certificados referentes al derecho real de superficie se registrarán y publicitarán en los rubros b), c) y d) de la matrícula específica del derecho real de superficie.

101.7. Los pedidos de publicidad con relación a la situación jurídica del inmueble, serán expedidos mediante las constancias que surjan de la totalidad de las matrículas.

101.8. La cancelación del derecho real de superficie por su extinción (por cualquier causa) deberá ser rogada expresamente y por documento idóneo presentado al efecto.

101.9. No será objeto de calificación registral el plazo de duración del derecho real de superficie.

En forma similar a los Cementerios Privados habrá una matrícula madre para la afectación al inmueble y otra matricula "SA" para el derecho de superficie.

El derecho real puede tener como fuente un contrato gratuito u oneroso. En materia de contraprestación del superficiario rige la autonomía de la voluntad, de allí que pueda consistir en el pago de una suma determinada de dinero, acordar la entrega de locales o espacios para el propietario para uso o arrendamiento a favor del propietario, que el dueño haga suyo lo plantado sin indemnización, o la reversión de lo edificado una vez concluida el derecho de superficie. Es importante pues, lo convenido en el título de constitución por la relevancia que tiene en la configuración del derecho.

Si el contrato es oneroso, se aplican supletoriamente las reglas de la compraventa (art 1124 inc. a), si es gratuito las reglas previstas para la donación (1543).

b) Actos de última voluntad

El derecho de superficie puede constituirse por testamento ${ }^{18}$ y si el superficiario muere , los herederos ocupan su lugar al tratarse de un derecho transmisible

c) Usucapión

El Código no permite la usucapión larga En cuanto a la prescripción breve la norma expresamente la regula a los fines del saneamiento de títulos.

18 Ello es así, en especial referencia a la norma que admite la constitución de superficie por disposición de última voluntad. Ver al respecto Kiper, Claudio, Obra citada, p 35. No compartimos las posturas que consideran que la disposición testamentaria en la superficie es dudosa por el carácter de orden público del derecho sucesorio. Al respecto ver Mariani de Vidal y Abella, obra citada, p.378. 


\section{$X$. Facultades del superficiario y del dominis solum}

Artículo 2120. Facultades del superficiario El titular del derecho de superficie está facultado para constituir derechos reales de garantía sobre el derecho de construir, plantar o forestar o sobre la propiedad superficiaria, limitados, en ambos casos, al plazo de duración del derecho de superficie. El superficiario puede afectar la construcción al régimen de la propiedad horizontal, con separación del terreno perteneciente al propietario excepto pacto en contrario; puede transmitir y gravar como inmuebles independientes las viviendas, locales u otras unidades privativas, durante el plazo del derecho de superficie, sin necesidad de consentimiento del propietario.

a) Uso, goce y disposición.

Las facultades materiales están contempladas en el artículo 2115 que dice: "El superficiario puede realizar construcciones, plantaciones o forestaciones haciendo propio lo plantada, forestado y construido..."

Es decir puede construir, plantar o forestar sobre el inmueble que pertenece a otro por encima o debajo del suelo y también sobre la rasante, también puede hacer suyo lo plantado, forestado o construido

Agrega la norma "...también puede constituirse el derecho sobre plantaciones, forestacioneso construcciones ya existentes, atribuyendo al superficiario su propiedad". En este caso el dueño conserva el derecho sobre el suelo.

Puede disponer jurídicamente de su derecho por actos entre vivos o disposición de última voluntad (art 2119).

b) Garantías reales

Puede constituir hipoteca (art 2206) y anticresis (2113), que no podrán durar más que el plazo máximo previsto para el derecho de superficie.

c) Acciones posesorias y reales

Podrá ejercer ambos tipos de acciones

d) Derechos personales

Puede constituir derechos personales tales como locación, comodato, etc.

Con respecto a las facultades del propietario:

Artículo 2121. Facultades del propietario El propietario conserva la disposición material y jurídica que corresponde a su derecho, siempre que las ejerza sin turbar el derecho del superficiario.

Conforme lo dispuesto por el citado artículo el propietario del suelo puede realizar actos de disposición material y jurídica respecto del inmueble, siempre que su ejercicio no afecte el derecho de propiedad. Así podría transmitir la nuda propiedad y constituir derechos personales o reales sobre el suelo o nuda propiedad que conserva.

Además cuenta también con defensas posesorias y reales. 


\section{Destrucccion de la propiedad superficiaria}

Al respecto el artículo 2122 regula:

Artículo 2122. Destrucción de la propiedad superficiaria La propiedad superficiaria no se extingue, excepto pacto en contrario, por la destrucción de lo construido, plantado o forestado, si el superficiario construye, nuevamente dentro del plazo de seis años, que se reduce a tres años para plantar o forestar.

La destrucción de la propiedad superficiaria no produce por sí misma la extinción del derecho de superficie, salvo pacto en contrario. El propósito de la norma es mantener el inmueble productivo., así al no extinguirse el derecho de superficie continúan intactas las obligaciones que hubieran asumido propietario y superficiario, salvo que el superficiario comience a realizar nuevas obras dentro de los plazos de seis y tres años, respectivamente para la construcciones o forestaciones o plantaciones. Entendemos que el plazo se cuenta desde la destrucción. ${ }^{19}$

El artículo 2123 aclara en relación a las obligaciones:

Artículo 2123. Subsistencia y transmisión de las obligaciones La transmisión del derecho comprende las obligaciones del superficiario. La renuncia del derecho por el superficiario, su desuso o abandono, no lo liberan de sus obligaciones legales o contractuales.

\section{Extincion}

Artículo 2124. Extinción El derecho de construir, plantar o forestar se extingue por renuncia expresa, vencimiento del plazo, cumplimiento de una condición resolutoria, por consolidación y por el no uso durante diez años, para el derecho a construir, y de cinco, para el derecho a plantar o forestar.

Al respecto se extingue por:

a) Renuncia expresa

Se descarta la renuncia tácita. ${ }^{20}$ La renuncia expresa debe pues hacerse por escritura pública.

La renuncia no libera al superficiario de sus obligaciones (art 2123).

b) Vencimiento del plazo

Se extingue por vencimiento del plazo contractual por el simple transcurso del tiempo o por falta de convenio por vencimiento de los plazos máximo (2117).

c) Por cumplimiento de una condición resolutoria

Las partes 'pueden pactarla, pero la condición que el nudo propietario imponga al superficiario puede dejarlo en un estado de inseguridad, razón por la cual es poco probable que se utilice en la práctica. La condición debería ser publicitada registralmente al igual que su cumplimiento a través una nota aclaratoria en el folio respectivo. ${ }^{21}$

19 En tal sentido Mariani de Vidal y Abella, obra citada, p. 386.

$20 \mathrm{Al}$ respecto el articulo 948 expresa que "La voluntad de renunciar no se presume y la interpretación de los actos que permiten inducirla es restrictiva"..

21 Kiper, Claudio, obra citada, p. 55.. 
d) Consolidación.

Por reunión en una misma persona, de las calidades de propietario del suelo y superficiario.

e) El no uso.

El Código regula la extinción por el no uso en relación al derecho de construir en el plazo de diez año y de plantar o forestar en el plazo de cinco.

La extinción deberá documentarse por escritura pública firmada por superficiario y propietario e inscribirse a los fines de la oponibilidad.

En cuanto a los efectos de la extinción se regula:

Artículo 2125. Efectos de la extinción Al momento de la extinción del derecho de superficie por el cumplimiento del plazo convencional o legal, el propietario del suelo hace suyo lo construido, plantado o forestado, libre de los derechos reales o personales impuestos por el superficiario. Si el derecho de superficie se extingue antes del cumplimiento del plazo legal o convencional, los derechos reales constituidos sobre la superficie o sobre el suelo continúan gravando separadamente las dos parcelas, como si no hubiese habido extinción, hasta el transcurso del plazo del derecho de superficie. Subsisten también los derechos personales durante el tiempo establecido.

Indemnización

El Código la regula en el siguiente artículo:

Artículo 2126. Indemnización al superficiario Producida la extinción del derecho de superficie, el titular del derecho real sobre el suelo debe indemnizar al superficiario, excepto pacto en contrario. El monto de la indemnización es fijado por las partes en el acto constitutivo del derecho real de superficie, o en acuerdos posteriores. En subsidio, a los efectos de establecer el monto de la indemnización, se toman en cuenta los valores subsistentes incorporados por el superficiario durante los dos últimos años, descontada la amortización.

Se establece la obligación del superficiario de indemnizar salvo pacto en contrario, aún pactarse que el nudo propietario se quede con las plantaciones o construcciones o bien fijar monto, pautas o procedimiento de la indemnización en el acto constitutivo.

En caso que esto no sucediere se tendrá en cuenta lo regulado en la última parte del artículo 2126.

XIII. Normas aplicables a la superficie. derecho de superficie y propiedad superficiaria.

Al respecto se regula:

Artículo 2127. Normas aplicables al derecho de superficie Son de aplicación supletoria las normas relativas a las limitaciones del uso y goce en el derecho de usufructo, sin perjuicio de lo que las partes hayan pactado al respecto en el acto constitutivo. 
Artículo 2128. Normas aplicables a la propiedad superficiaria Si el derecho de superficie se ejerce sobre una construcción, plantación o forestación ya existente, se le aplican las reglas previstas para el caso de propiedad superficiaria, la que a su vez queda sujeta a las normas del dominio revocable sobre cosas inmuebles en tanto sean compatibles y no estén modificadas por las previstas en este Título

\section{Implicancia economica e importancia del rol del escribano}

1.1. Consideramos que el derecho real de superficie es la herramienta adecuada para conseguir financiamiento para la realización de costosas obras cuando no se es el titular de dominio del inmueble, ya que éste tiene la posibilidad de gravar con hipoteca su derecho real.

1.2 Es así que resulta relevante pensar en nuevas posibilidades de realizar negocios inmobiliarios con esta figura. Ejemplos de ellos podemos encontrarlos, en la búsqueda de nuevas energías que sean renovables y que afecten menos el medio ambiente lo cual va cobrando cada día más importancia en el mundo, siendo costosa la aplicación de las nuevas tecnologías. Es por ello que para incentivar a que las empresas y personas humanas apuesten a ellas, se necesita un marco jurídico seguro y viable para la inversión. Podemos pensar en la instalación de molinos de viento que permitan la recepción de la energía eólica, los propietarios podrían afectar una franja delimitada de su propiedad para la instalación en la misma de molinos que permitan la recepción del viento y poder generar de esta manera energía eólica. Este recurso que se generaría quedaría a cargo del superficiario, ya sea su recolección almacenamiento y comercialización, vencido el plazo el propietario podría abonarle una indemnización conforme a los parámetros establecidos al final del artículo 2126 del Código Civil y Comercial de la Nación.

También puede utilizarse esa figura aplicado a la construcción de un emprendimiento: Por ejemplo se podría implementar para el desarrollo de un Centro Comercial, donde hay un conjunto de propietarios que tienen la tierra pero no tienen dinero para llevar a cabo la construcción de los locales, patio de comida, estacionamiento. Entonces se podría delegar la construcción del predio a otra persona, ya sea humana o jurídica. El superficiario se encargaría de la construcción y como contraprestación podría obtener el beneficio que se genere por el alquiler de dichos locales por determinado tiempo. Al finalizar el contrato el propietario se quedaría con los locales y a cambio podría indemnizar al superficiario con la entrega de algunos locales.

Otros ejemplos los encontramos en las cocheras. Sabemos que cada día hay mayor cantidad de vehículos y que existe ya hoy un déficit importante de las misma. El propietario de un lote de terreno, que planea edificar sobre el suelo del mismo, podría constituir derecho de superficie a favor de un tercero y delimitar el espacio existente en el subsuelo de la propiedad para la creación de las cocheras. Durante el derecho de superficie, el superficiario se quedaría con las utilidades o rentas de las cocheras y vencido el plazo el propietario contará con las cocheras. Esto nos llevaría al interrogante si un mismo propietario puede constituir dos o varios derechos de superficie distintos sobre una misma propiedad al mismo tiempo, es decir uno en el espacio aéreo y otro en el subsuelo. A este interrogante consideramos que sí se podría y que no habría ninguna incompatibilidad en la medida en que al constituirse el derecho de superficie en ambos casos se deje asentado con plano pertinente y demás requisitos especificados más arriba para la constitución 
que superficie será específicamente la afectado ya sea determinarse tanto en sentido horizontal como vertical.

\section{Conclusion.}

Entendemos pues, que la aplicación del derecho de superficie a distintas actividades negociables nos abre un gran abanico de posibilidades, tiene aptitud para reactivar más sectores de la producción, como pueden ser, la construcción la cual -es bien sabido- tiene un gran efecto multiplicador de la riqueza, en la cuales el escribano deberá conocer en profundidad la normativa de fondo del Código Civil y Comercial, además de las disposiciones catastrales y registrales, precedentemente expuestas. 